Old Dominion University

ODU Digital Commons

OEAS Faculty Publications

Ocean, Earth \& Atmospheric Sciences

$8-2000$

\title{
Alteration Processes of Alkenones and Related Lipids in Water Columns and Sediments
}

H. Rodger Harvey

Old Dominion University, rharvey@odu.edu

Follow this and additional works at: https://digitalcommons.odu.edu/oeas_fac_pubs

Part of the Biogeochemistry Commons, Geophysics and Seismology Commons, Oceanography Commons, and the Sedimentology Commons

\section{Repository Citation}

Harvey, H. Rodger, "Alteration Processes of Alkenones and Related Lipids in Water Columns and Sediments" (2000). OEAS Faculty Publications. 159.

https://digitalcommons.odu.edu/oeas_fac_pubs/159

\section{Original Publication Citation}

Harvey, H.R. (2000). Alteration processes of alkenones and related lipids in water columns and sediments. Geochemistry, Geophysics, Geosystems, 1(8). doi: 10.1029/2000GC000054

This Article is brought to you for free and open access by the Ocean, Earth \& Atmospheric Sciences at ODU Digital Commons. It has been accepted for inclusion in OEAS Faculty Publications by an authorized administrator of ODU Digital Commons. For more information, please contact

digitalcommons@odu.edu. 


\title{
Alteration processes of alkenones and related lipids in water columns and sediments
}

\author{
H. Rodger Harvey \\ Chesapeake Biological Laboratory, University of Maryland Center for Environmental Science, P.O. Box 38, \\ Solomons, Maryland 20688 (harvey@cbl.umces.edu)
}

[1] Abstract: Alkenones produced by the haptophyte algae are currently being used as indices of sea surface temperature in recent and past ocean environments, but limited information is available concerning the impact of biotic and abiotic processes on the integrity of these long chain lipids. This synthesis provides selected background information on major alteration processes that must be considered before such indices can be used with confidence. A number of processes in the water column and surface sediments have the potential to impact the structural integrity of alkenones and compromise their ability as temperature markers. Processes discussed include the alteration of alkenone structure during early diagenesis, direct biotic and abiotic impacts, and the effect of digestive processes by grazers. Current literature suggests that despite substantial changes in concentration from biological processing, the temperature signal is preserved. For each of these processes, information on the integrity of the alkenone isotopic signature is also needed and limited information available is reviewed. In addition to the alkenones, related lipids including the long chain alkadienes and akyl alkenoates that might serve as ancillary markers are discussed.

Keywords: Alkenone; lipids; paleoclimate; diagenesis; sea surface temperature.

Index Terms: Climate and interannual variability; paleoceanography; biogeochemical processes; organic marine chemistry.

Received February 22, 2000; Revised July 21, 2000; Accepted July 28, 2000; Published August 21, 2000.

Harvey, H. R., 2000. Alteration processes of alkenones and related lipids in water columns and sediments, Geochem. Geophys. Geosyst., vol. 1, Paper number 2000GC000054 [3634 words]. Published August 21, 2000.

Theme: Alkenones Guest Editor: John Hayes

\section{Introduction}

[2] The use of molecular organic markers has provided valuable information on a wide range of inputs and processes that occur in the oceans and sediments. To exploit fully the utility of such analyses, we must understand the impact of biological processing in the water column and surface sediments on the molecular signal that is ultimately preserved in the geological record. Such information is critically important for the alkenones and related lipids of the haptophyte algae currently being used in a range of oceanic environments to detail both present and historical records of sea surface temperature. To provide background information for the discussion of working group 4 (Alteration processes: water column and sediments), this paper summarizes information about the environmental fate of alkenones and 
related lipids in the water column and surface sediments. It is not meant to be an exhaustive review of the literature but rather a starting point for the group discussion held during the workshop. In particular, it highlights areas where information is needed or consensus is required to better link the signal formed during alkenone biosynthesis with the ratios preserved in the geological record.

\section{Scientific Background}

[3] The long chain alkenones have the unique potential to act as specific indicators of past sea surface temperatures. The structure of these lipid biomarkers was first described by de Leeuw et al.[1980] after isolation from sediments of the Black Sea and from Walvis Ridge. Coincident with the isolation of these long chain $\left(\mathrm{C}_{37}-\mathrm{C}_{39}\right)$ di-, tri-, and tetraunsaturated ethyl and methyl ketones (the alkenones) was the report of their presence together with the structurally related alkyl alkenoates and the long chain alkenes in the oceanic coccolithophorid Emiliania huxleyi [Volkman et al., 1980]. They were later identified in four other members of the Prymnesiophyceae including the coastal species Isochrysis galbana [Marlowe et al., 1984; Patterson et al., 1994]. E. huxleyi appears the dominant source of these compounds in the open ocean, although these compounds also occur in the closely related species Gephyrocapsa oceanica [Conte et al., 1995; Volkman et al., 1995].

[4] Since the alkenones discovery, further investigation has shown that ratios of these unique cellular components can provide a reliable indicator of the temperature of their biosynthesis. Marlowe et al. [1984] initially observed that the degree of unsaturation reflected the temperature at which cultures were grown. Specifically, the algae that contain these lipids adapt to changes in water temperature by increasing the number of unsaturated positions in the alkenones as temperature decreases. Brassell et al. [1986] first used this relationship to correlate the unsaturation ratio of alkenones with the overlying sea surface temperature (SST). They defined the alkenone unsaturation index (the $\mathrm{U}_{37}{ }^{\mathrm{k}}$ ) as the ratio of ([37:2] $[37: 4]) /([37: 2]+[37: 3]+[37: 4])$ alkenones isolated and quantified from sediments. Downcore variations in $\mathrm{U}_{37}{ }^{\mathrm{k}}$ in sediments of Quaternary age from the equatorial West Atlantic coincided with changes in the oxygen isotopic compositions of planktonic foraminiferas, supporting the hypothesis that the ratio among these compounds preserves a record of sea surface temperatures at the time of biosynthesis. Further intercalibration studies using both cultures and field collections [Prahl and Wakeham, 1987] confirmed the linear relationship of unsaturation and growth temperature over at least the $8^{\circ}-25^{\circ} \mathrm{C}$ range in open ocean systems. The modified ratio that excludes the highly unsaturated 37:4 member of the series is termed $\mathrm{U}_{37}{ }^{\mathrm{k}^{\prime}}$ and most widely used.

\section{Discussion}

\subsection{Impact of Early Diagenesis}

[5] Despite their widespread use as markers of SST, alkenones, similar to most organic molecules, are susceptible to alteration in the environment. Measured concentrations decrease significantly during early diagenesis. For other lipids, decreases in amount are usually accompanied by the preferential loss of more unsaturated moieties. Taken together, the decrease in concentration and potential for selective losses raise a significant concern about the preservation of initial, biosynthetically established levels of unsaturation. Early field observations, however, found encouraging results on the integrity of the alkenone ratio. Samples of turbidites from the Madeira Abyssal Plain (MAP) examined by Prahl et al. [1989] showed that while concentrations declined with sediment 
depth (up to $85 \%$ over $\sim 8 \mathrm{kyr}$ in oxidized sediments), alkenone abundance ratios in sediments appeared to be stable under both oxic and reduced conditions. Methodological considerations (i.e., carbonate dissolution, sample storage) studied by Sikes et al. [1991] also supported the resistance of the alkenone ratio to alteration once incorporated in sediments. Subsequent observations by others noted that alkenone concentrations sharply decrease below the sediment-water interface [e.g., Kennedy and Brassell, 1992; Conte et al., 1992], suggesting that degradation in the early stages of diagenesis might still be a concern. Further work by Prahl et al. [1993] affirmed the need for information on the stability of alkenones and the influence of biological processing on their stability. In that study, samples were collected from the Northwest Pacific during the Multitracers project from both moored sediment traps and box cores and included analysis of alkenones, total organic carbon (TOC), and $\mathrm{CaCO}_{3}$. Although the flux of carbonate and organic carbon were strongly correlated $\left(r^{2}=0.67\right)$, alkenone flux showed a poor relationship with either TOC or $\mathrm{CaCO}_{3}$ flux $\left(r^{2}=0.17\right.$ and 0.014 respectively). Further, relative concentrations of alkenones in sediment traps and bottom sediments suggested that the alkenones were at least as labile as TOC and only a small fraction of alkenones collected in traps $(0.25$ to $22 \%)$ was preserved in surface sediments. The importance of biotic and abiotic alterations as concentrations decrease raises the concern that more unsaturated components could be selectively lost or modified, altering the ratio and thus their ability to provide molecular markers of sea surface temperature. Results contrasting those of Prahl et al. [1989] were reported by Hoefs et al. [1998], who also analyzed the MAP turbidites (although at different sections) and suggested that oxidation involved significant changes in the $\mathrm{U}_{37}{ }^{\mathrm{K}^{\prime}}$. Grimalt et al. [2000] has recently examined the analytical constraints for $\mathrm{U}_{37}{ }^{\mathrm{K}^{\prime}}$ and suggested that the results of Hoefs et al. [1998] could be compromised by analytical measurements near the detection limit. Gong and Hollander [1999] examined sediment profiles in the Santa Monica Basin and suggested that differential degradation of alkenones might occur in sediments dependent upon oxygen content. It seems that all is not resolved.

[6] We will begin our group discussion with two linked hypotheses to consider as critical tests of the utility of alkenones for paleotemperature reconstruction: (1) Alkenones and related organic structures are sensitive to biotic and abiotic alterations in the water column and surface sediments, but (2) such alteration processes do not affect the temperature signal established during their initial biosynthesis. For alkenones and the related lipids to be useful as measures of SST in the geological record, the preservation of the molecular signal and the effects of environmental conditions on preservation need to be understood.

\subsection{Direct Measures of Biotic Alteration}

[7] Empirical measures of the effects of biological diagenesis on the temperature signal preserved in the alkenones have recently appeared in the literature. Microbial degradation experiments of $\mathrm{C}_{37}$ alkenones under oxic, sulphatereducing, and methanogenic conditions in batch mode find that the alkenones are degraded more slowly that most other lipids [Teece et al., 1995, 1998]. More importantly, values of $\mathrm{U}_{37}{ }^{\mathrm{K}^{\prime}}$ did not vary under the conditions used. Losses of related lipids as the $\mathrm{C}_{31}$ alkadienes were more rapid, especially under oxic conditions. This may be due to their cis configuration, the $\mathrm{C}_{37}$ alkadienes containing all E (trans) double bonds [Rieley et al., 1998] were degraded more slowly. Unfortunately, initial concentrations of the tetraunsaturated ketone in these experiments were so low that its lability could not be determined. Harvey and Ederington-Hagy [1999] used flow-through 
systems to simulate sedimentation of decaying cells and exposure to natural bacterial assemblages. Their results also showed that the $\mathrm{U}_{37}{ }^{\mathrm{K}^{\prime}}$ was preserved under oxic and anoxic conditions. In general agreement with the work of Teece et al. [1998], alkadienes were degraded at much faster rates when oxygen was present. In these experiments, cultures were grown and degradation was conducted at $8^{\circ} \mathrm{C}$, and thus information on highly unsaturated forms was also obtained. Under both oxic and anoxic conditions, the 37:4 alkenone was degraded more rapidly than the more saturated $37: 2$ and 37:3 alkenones.

\subsubsection{Effects of Grazers}

[8] Lipids composition is altered by zooplankton grazers, often with the selective loss of more unsaturated forms [e.g., Harvey et al., 1987]. Early work of Volkman et al. [1980] suggested that the alkenones might be the exception to this general rule, finding $\mathrm{U}_{37}{ }^{\mathrm{K}^{\prime}}$ values in fecal pellets of Calanus helgolandicus equal to those in Emiliania huxleyi provided as food. Subsequent work established that the double-bond configuration were all of the E configuration (trans [Rechka and Maxwell, 1988]) and provided a possible explanation, because digestive enzymes typically show strong preference for the cis forms. Recent feeding experiments using Isochrysis galbana fed to the coastal copepod Temora longicornis [Grice et al., 1998] did not find significant changes in $\mathrm{U}_{37}{ }^{\mathrm{K}^{\prime}}$ upon ingestion. The authors also reported no significant changes in ${ }^{13} \mathrm{C}$ alkenone composition upon ingestion by these copepods. The effect of microbial and higher-level grazers on alkenones and related lipids is a key subject for consideration by this working group.

\subsubsection{Abiotic Alteration}

[9] The effects of nonbiological processes on values of $\mathrm{U}_{37}{ }^{\mathrm{K}^{\prime}}$ have not been extensively explored. A laboratory experiment by Rontani et al. [1997] did examine photochemical effects in broken cells of Emiliania huxleyi exposed to degradation by light for up to 21 days. Losses of alkenones were significant, but values of $\mathrm{U}_{37}{ }^{\mathrm{K}^{\prime}}$ changed by less than 0.04 . These results, taken together with the absence of labile chromophores in these compounds, suggest that a photochemical effect on $\mathrm{U}_{37}{ }^{\mathrm{K}^{\prime}}$ may be absent. Selective sulfurization of more highly unsaturated alkenones under anoxic conditions may be a more significant abiotic process and merits further consideration.

\subsubsection{Isotopic Alteration}

[10] The isotopic integrity observed by Grice et al. [1998] with feeding experiments suggests that changes in isotopic abundance may not be a significant during early diagenesis of alkenones. The similar rates of loss for many of the alkenones during microbial degradation [Teece et al., 1998; Harvey and Ederington-Hagy, 1999] infer that if isotopic changes do occur, they will be consistent among structures and thus predictable. Examining alkenones from particulates in surface waters of the Black Sea, Freeman and Wakeham [1992] observed concentrations to decrease several orders of magnitude with depth, significantly greater than total particulate organic carbon. Isotopic compositions also changed, raising the possibility that isotopically selective degradative processes had been detected. Notably, $\mathrm{U}_{37}{ }^{\mathrm{K}^{\prime}}$ values increased with water depth even though temperatures actually decreased and the isotopic composition of the 37:4 alkenone diverged from those of the $37: 2$ and $37: 3$. Although several causes for these inconsistencies have been put forth, including multiple haptophyte sources, biosynthetic shifts, and preferential degradation, little empirical information is available to date to support any firm conclusions. For example, it remains uncertain whether the enhanced loss of more unsaturated species via sulfurization of double bonds below 
the oxic-anoxic interface might account for the discrepancy. In general, however, diagenetic alterations of the isotopic composition of alkenones are expected to be small, given that isotopic selectivity would occur at one, or possibly two, carbon atoms. Even if fractionation at a single carbon atom is large, the effect on the overall isotopic composition of the 37carbon molecule will be minor. This working group will not address controls over the alkenone isotopic signal during biosynthesis but will discuss the alkenone isotopic preservation during early diagenesis.

[11] The preferential loss of unsaturated components, whether by binding through reactive sulfur in anoxic waters or by biological diagenesis in the marine water column, is particularly important in high latitudes (and thus lower temperatures), where greater amounts of the more unsaturated 37:4 alkenone are synthesized. Sikes and Volkman [1993] have noted that while alkenone ratios of particulates collected from surface waters in the Southern Ocean show excellent agreement with the calibration of Prahl and Wakeham [1987] for many temperatures, it departs from linearity below $5^{\circ} \mathrm{C}$. The large scatter in the data below $5^{\circ} \mathrm{C}$ could have multiple causes, but the near absence of the 37:4 alkenone, whose concentrations should increase in cold waters, could be a result of its loss during diagenesis or formation of related structures in surface waters due to biological alteration. As a result, the 37:4 alkenone has important implications for examining the productivity and SST calibration of the haptophytes at high latitudes. The fate of the 37:4 alkenone verses other alkenones will be included as a specific topic discussed by the working group.

\subsubsection{Related Lipids and Their Alteration}

[12] In addition to the alkenones and alkyl alkenoates, related lipid biomarkers could play an important role in defining the haptophyte community or as alternative calibrations for paleotemperature estimations. As the most cosmopolitan member of the prymnesiophytes, $E$. huxleyi also contains a number of long chain hydrocarbons, in particular, the $\mathrm{C}_{31}$ to $\mathrm{C}_{38}$ alkenes [Volkman et al., 1980; Teece et al., 1998]. Related structures have also been observed in Isochrysis galbana found in coastal waters [Marlowe et al., 1984]. Together with the alkenones, Sikes et al. [1997] observed the unsaturated $\mathrm{C}_{37}$ and $\mathrm{C}_{38}$ hydrocarbons in substantial concentrations in the Southern Ocean, which they argued might represent potential intermediates or substitutes for alkenones in polar waters. F. G. Prahl et al. (personal communication, 1999) have observed that ratios of these alkenes vary among different clones of $E$. huxleyi and suggest that their presence may serve to define the contribution of differing clones to the alkenone signal. While this is clearly a promising area for refining the alkenone calibration and potentially for a new set of paleotemperature markers, alkenes will only prove useful if degradation rates in the water column and sediments are predictable and the kinetics of loss are known. Their potential importance as source and/or calibration markers for the haptophytes requires information on their stability or formation in the water column and surface sediments. The preservation of these lipids as ancillary markers will be included in the group discussion.

\section{Concluding Remarks}

[13] It is evident that refinement of the alkenones and potentially other molecular organic markers as proxies of sea surface temperature will require a number of approaches. These might range from the examination of genetic and clonal diversity among the algae that produce these compounds to more detailed calibrations with inorganic indices of past sea surface temperature (e.g., $\left.{ }^{18} \mathrm{O}\right)$. It is in the water 
column and surface sediments where concentrations of these compounds are subject to the greatest change, and our discussion group will focus on the biotic and abiotic changes that might impact their use as paleoenvionmental proxies. This group also will include in our discussions how best to link measures of the alteration processes and their direct impact on alkenone ratios seen in the field. As several members of the group have already noted prior to the workshop, oceanographic processes at multiple timescales will alter the signal ultimately preserved in the sedimentary record and must be included as part of our synthesis.

\section{Acknowledgments}

[14] This summary benefited from helpful comments by members of Working Group 4 (J. Grimalt, J. Farrington, M. Goñi, J, Rullkötter, K. Sawada, M-A Sicre, and R. Summons), in particular, Joan Grimalt, who provided helpful background information and many useful suggestions. John Hayes, Stuart Wakeham, and Mark Teece provided valuable reviews and suggestions for improvement. The workshop organizers and NSF are thanked for the invitation to participate and travel support.

\section{References}

Brassell, S. C., R. G. Brereton, G. Eglinton, J. O. Grimalt, G. Liebezeit, I. T. Marlowe, U. Pflaumann, and M. Sarnthein, Palaeoclimatic signals recognized by chemometric treatment of molecular stratigraphic data, Org. Geochem., 10, 649-660, 1986.

Conte, H. M., G. Eglinton, and L. A. S. Madureira, Long-chain alkenones and alkyl alkenoates as palaeotemperature indicators: Their production, flux and early sedimentary diagenesis in the Eastern North Atlantic, Org. Geochem., 19, 287-298, 1992.

Conte, M. H., A. Thompson, G. Eglinton, and J. C. Green, Lipid biomarker diversity in the coccolithophorid Emiliania-huxleyi (Prymnesiophyceae) and the related species Gephyrocapsa-oceanica, J. Phycol., 31, 272-282, 1995

de Leeuw, J. W., F. W. Van Der Meer, W. I. C. Rijpstra, and P. A. Schenck, On the occurrence and structural identification of long chain unsaturated ketones and hydrocarbons in sediments, in Advances in Organic Geochemistry 1979, edited by A. G. Douglas and J.
R. Maxwell, pp. 211-217, Pergamon, Tarrytown, New York, 1980.

Freeman, K. H., and S. G. Wakeham, Variations in the distributions and isotopic compositions of alkenones in Black Sea particles and sediments, Org. Geochem., 19, 277-285, 1992.

Gong, C., and D. J. Hollander, Evidence for differential degradation of alkenones under contrasting bottom water oxygen conditions implication for paleotemperature reconstruction, Geochim. Cosmochim. Acta., 63, 405-411, 1999.

Grice, K., W. C. M. K. Breteler, S. Schouten, and V. Grossi, Effects of zooplankton herbivory on biomarker proxy records, Paleceanography, 13, 686-693, 1998.

Grimalt, J. O., H. R. Harvey, J. Farrington, M. Goñi, J. Rullkötter, K. Sawada, M.-A. Sicre, and R. Summons, Modifications of the $\mathrm{C}_{37}$ alkenone and alkenoate composition in the water column and sediment: Possible implications for sea surface temperature estimates in paleoceanography, Geophys. Geochem. Geosyst., in press, 2000.

Harvey, H. R., G. Eglinton, S. C. M. O'Hara, and E. D. S. Corner, Biotransformation and assimilation of dietary lipids by Calanus feeding on a dinoflagellate, Geochim. Cosmochim. Acta, 51, 3031-3040, 1987.

Harvey, H. R., and M. Ederington-Hagy, Molecular integrity of alkenones and related lipids during early diagenesis, poster presented at National Science Foundation Workshop on Alkenone-Based Paleoceanographic Indicators, Woods Hole, Mass., Oct. 1999.

Hoefs, M. J. L., G. J. M. Versteegh, W. I. C. Rijpstra, J. W. de Leeuw, and J. S. Sinninghe Damste, Postdepositional oxic degradation of alkenones: Implications for the measurement of palaeo sea surface temperatures, Paleoceanography, 13, 42-49, 1998.

Kennedy, J. A., and S. C. Brassell, Molecular records of 20th-Century El-Nino events in laminated sediments from the Santa-Barbara Basin, Nature, 357, 62-64, 1992.

Madureira, L. A. S., M. H. Conte, and G. Eglinton, Early diagenesis of lipid biomarker compounds in North Atlantic sediments, Paleoceangraphy, 10, 627-642, 1995.

Marlowe, I. T., S. C. Brassel, G. Eglinton, and J. C. Green, Long chain unsaturated ketones and esters in living algae and marine sediments, Org. Geochem., 6, 135-141, 1984.

Patterson, G. W., E. Tsitsa-Tsardis, G. H. Wikfors, P. K. Gladu, D. J. Chitwood, and D. Harrison, Sterols and alkenones of Isochrysis, Phytochemistry, 35, 12331236, 1994.

Prahl, F. G., and S. G. Wakeham, Calibration of unsaturation patterns in long-chain ketone composi- 
tions or palaeotemperature, Nature, 330, 367-369, 1987.

Prahl, F. G., L. A. Muehlhausen, and D. L. Zahnle, Further evaluation of long-chain alkenones as indicators of paleoceanographic conditions, Geochim. Cosmochim. Acta, 52, 2303-2310, 1988.

Prahl, F. G., G. J. de Lange, M. Lyle, and M. A. Sparrow, Post-depositional stability of long-chain alkenones under contrasting redox conditions, Nature, 341, 434-437, 1989.

Prahl, F. G., R. B. Collier, J. Dymond, M. Lyle, and M. A. Sparrow, A biomarker perspective on prymnesiophyte productivity in the northeastern Pacific Ocean, Deep Sea Res, Part I, 40, 2061-2076, 1993.

Rechka, J. A., and J. Maxwell, Unusual long chain ketones of algal origin, Tetrahedron Lett., 29, 2599-2600, 1988.

Rieley, G., M. A. Teece, T. M. Peakman, A. M. Raven, K. J. Greene, T. P. Clarke, M. Murray, J. W. Leftley, C. N. Campbell, R. P. Harris, R. J. Parkes, and J. R. Maxwell, Long-chain alkenes of the haptophytes Isochrysis galbana and Emiliania huxleyi, Lipids, 33, 617-625, 1998.

Rontani, J. F., et al., Stability of long-chain alkenones in senescing cells of Emiliania huxleyi: Effect of photochemical and aerobic microbial degradation on the alkenone unsaturation ratio (U- 37( $\left(\mathrm{k}^{\prime}\right)$ ), Org. Geochemistry, 26, 503-509, 1997.

Sikes, E. L., and J. K. Volkman, Calibration of alkenone unsaturation ratios $\left(\mathrm{U}-37\left(\mathrm{~K}^{\prime}\right)\right)$ for paleotemperature estimation in cold polar waters, Geochim. Cosmochim. Acta, 57, 1883-1889, 1993.

Sikes, E. L., J. W. Farrington, and L. D. Keigwin, Use of the alkenone unsaturation ratio $\mathrm{U}_{37}{ }^{\mathrm{K}}$ to determine past sea surface temperatures: Core-top SST calibrations and methodology considerations, Earth Planet. Sci. Lett., 104, 36-47, 1991.

Sikes, E. L., J. K. Volkman, L. G. Robertson, and J.-J. Pichon, Alkenones and alkenes in surface waters and sediments of the Southern Ocean: Implications for paleotemperature estimation in polar regions, Geochimica et Cosmochimica Acta, 61, 1495-1505, 1997.

Teece, M. A., J. M. Getliff, J. W. Leftley, R. J. Parkes, and J. R. Maxwell, Microbial processes involved in the degradation and survival of algal lipid biomarkers, in Organic Geochemistry: Developments and Applications to Energy, Climate, Environment and Human History, edited by J. O. Grimalt and C. Dorronsoro, pp. 898-901, AIGOA, Donostia-San Sebastian, Spain, 1995.

Teece, M. A., J. M. Getliff, J. W. Leftley, R. J. Parkes, and J. R. Maxwell, Microbial degradation of the marine prymnesiophyte Emiliania huxleyi under oxic and anoxic conditions as a model for early diagenesis: long chain alkadienes, alkenones and alkyl alkenoates, Org. Geochem., 29, 863-880, 1998.

Volkman, J. K., G. Eglinton, E. D. S. Corner, and J. R. Sargent, Novel unsaturated straight-chain methyl and ethyl ketones in marine sediments and a coccolithophore Emiliania huxleyi, in Advances in Organic Geochemistry 1979, edited by A. G. Douglas and J. R. Maxwell, pp. 219-227, Pergamon, Tarrytown, New York, 1980

Volkman, J. K., S. M. Barrett, S. I. Blackburn, and E. L. Sikes, Alkenones in Gephyrocapsa-Oceanica - Implications for studies of paleoclimate, Geochim. Cosmochim. Acta, 59, 513-520, 1995. 